\title{
Suplementação de bezerras de corte lactentes em sistema de creep- feeding e parâmetros nutricionais e produtivos de vaca de corte em pastejo
}

\section{Supplementation of female calves in creep feeding system and productive and nutritional parameters of beef cows on tropical pasture}

\author{
Lívia Vieira de Barros ${ }^{1 *}$; Mário Fonseca Paulino²; Mário Luiz Chizzotti²; \\ Luciana Navajas Rennó ${ }^{2}$ Javier Enrique Garces Cardenas ${ }^{3}$; \\ Eriton Egidio Lisboa Valente ${ }^{4}$; Sidnei Antônio Lopes ${ }^{3}$; \\ Carla Heloisa Avelino Cabral ${ }^{5}$; Nelcino Francisco de Paula ${ }^{6}$; \\ Felipe Gomes da Silva ${ }^{6}$
}

\begin{abstract}
Resumo
Objetivou-se avaliar o desempenho produtivo e nutricional de bezerras lactentes recebendo mistura mineral ou suplementos múltiplos e a produção de leite, o consumo e a digestibilidade do pasto consumido por vacas de corte, em pastagens de Uruchloa decumbens. Utilizaram-se 48 bezerras de corte, lactentes, com idade média de 5 meses e peso médio inicial de $125,4 \pm 1,34 \mathrm{~kg}$, e suas respectivas mães com peso inicial médio de 435,2 $\pm 10,3 \mathrm{~kg}$. O delineamento experimental foi o inteiramente casualizado. Os suplementos continham aproximadamente $25 \%$ de proteína bruta (PB) e substituição progressiva do farelo de soja (FS) pelo farelo de algodão 38\% (FA) aos níveis de $0 ; 33 ; 67$ e 100\% para os tratamentos $\mathrm{FA}_{0}, \mathrm{FA}_{33}, \mathrm{FA}_{67}$ e $\mathrm{FA}_{100}$, respectivamente. Adicionou-se ureia aos suplementos visando ajustar o teor proteico dos suplementos. Os animais do tratamento controle (MM) receberam exclusivamente mistura mineral ad libitum; nos demais tratamentos os suplementos múltiplos foram fornecidos na quantidade de $0,5 \mathrm{~kg} /$ animal/dia. O ganho médio diário (g) foi 687,8; 733,2; 820,0; 760,6 e 764,5, respectivamente, para os tratamentos $\mathrm{MM}, \mathrm{FA}_{0}, \mathrm{FA}_{33}, \mathrm{FA}_{67}$ e $\mathrm{FA}_{100}$ As bezerras suplementadas apresentaram maior ganho em peso. Não se verificou efeito dos níveis de FA nos suplementos múltiplos $(\mathrm{P}>0,10)$ sobre o ganho médio diário. Os consumos em $\mathrm{kg} /$ dia de matéria seca (MS), matéria orgânica $(\mathrm{MO})$, proteína bruta $(\mathrm{PB})$, carboidratos não fibrosos (CNF), MS digerida e nutrientes digestíveis totais foram superiores $(\mathrm{P}<0,10)$ em animais suplementados com suplementos múltiplos em relação aos animais suplementados apenas com mistura mineral. Entre os níveis de substituição do FS por FA observou-se efeito linear decrescente com o aumento do nível de FA sobre o consumo de MS digerida e fibra em detergente neutro digerida. Os coeficientes de digestibilidade aparente total da MS, MO, PB e CNF foram superiores $(\mathrm{P}<0,10)$ em animais suplementados. Entre os níveis de substituição do FS pelo FA observou-se efeito linear decrescente sobre a digestibilidade da fibra em detergente neutro. A suplementação das bezerras não influenciou o desempenho das vacas, a produção de leite e o consumo
\end{abstract}

\footnotetext{
${ }^{1}$ Prof ${ }^{\text {a }}$ Universidade do Estado de Mato Grosso, UNEMAT, Cáceres, MT. E-mail: barrosufv@yahoo.com.br

${ }^{2}$ Profs., Universidade Federal de Viçosa, UFV, Viçosa, MG. E-mail: mpaulino@ufv.br; mariochizzotti@ufv.br; lucianarenno@ufv.br

${ }^{3}$ Discentes, UFV, Viçosa, MG. E-mail: jojavier1@hotmail.com; sidneyufv@hotmail.com

${ }^{4}$ Prof. Universidade Estadual do Paraná, UNIOESTE, Marechal Candido Rondon, PR. E-mail: eritonvalente@yahoo.com.br

${ }^{5}$ Prof ${ }^{\text {a }}$ Universidade Federal do Mato Grosso, UFMT, Rondonópolis, MT. E-mail: cabralcha@hotmail.com

${ }^{6}$ Profs., UFMT, Cuiabá, MT. E-mail: nelcinodepaula@hotmail.com; felipe.melhoramento@hotmail.com

* Autor para correspondência
} 
de componentes da dieta pelas vacas $(\mathrm{P}>0,10)$. Conclui-se que a utilização de suplementos múltiplos no período pré-desmama, propicia maior ganho de peso às bezerras.

Palavras-chave: Creep-feeding, consumo, desempenho, digestibilidade, Nelore

\begin{abstract}
The performance of female calves in creep-feeding system receiving only mineral mixture or multiple supplements; and milk production and pasture intake and digestibility of beef cows on Urochloa decumbens pastures, were assessed. Forty-eight suckling female calves aged 5 months on average, with an initial weight of $125.4 \pm 1.34 \mathrm{~kg}$, and their respective mothers initially weighing $435.2 \pm 10.3 \mathrm{~kg}$, were used. The experimental design was completely randomized. Supplements contained approximately $25 \%$ crude protein (CP) and a progressive substitution of soybean meal (SM) by cottonseed meal $38 \%$ protein $(\mathrm{CM})$ at the levels of $0,33,67$ and $100 \%$ for treatments $\mathrm{CM}_{0}, \mathrm{CM}_{33}, \mathrm{CM}_{67}$ and $\mathrm{CM}_{100}$, respectively. Urea was added to supplements in order to adjust the protein content of the supplements .In the control-group (MM) animals were fed only mineral mixture, ad libitum. The average daily gain (in g) was 687.8, 733.2, 820.0, 760.6 and 764.5, respectively, for treatments $\mathrm{MM}, \mathrm{CM}_{0}, \mathrm{CM}_{33}, \mathrm{CM}_{67}$ and $\mathrm{CM}_{100}$. Female calves supplemented with multiple supplements showed highest weight gain. No effect of CM levels in the multiple supplement were verified ( $\mathrm{P}>0.10)$ on average daily gain. The intakes in $\mathrm{kg} /$ day of dry matter $(\mathrm{DM})$, organic matter $(\mathrm{OM})$, crude protein (CP), non-fibrous carbohydrates (NFC), digested DM and total digestible nutrients were superior $(\mathrm{P}<0.10)$ for animals supplemented with multiple supplement in relation to control animals. Total apparent digestibility coefficients of DM, OM, CP and NFC were higher $(\mathrm{P}<0.10)$ for supplemented animals. The use of supplementation for female calves did not affect performance of cows, milk yield or ingestion of dietary components $(\mathrm{P}>0.10)$. As a conclusion, utilizing multiple supplements in the pre-weaning period provides highest weight gain to female calves.
\end{abstract}

Key words: Digestibility, intake, pasture, performance, Nellore

\section{Introdução}

O leite é a principal fonte de energia e nutrientes para os bezerros. Entretanto, à medida que o animal cresce, as exigências nutricionais aumentam e o consumo de leite diminui. Nos sistemas de produção de gado de corte, o leite produzido pelas matrizes não é suficiente para atender as exigências nutricionais dos bezerros a partir dos três meses de idade (HENRIQUES et al., 2011). No Brasil, a diminuição da produção de leite ocorre durante o período de transição águas-seca, período em que ocorre a diminuição na qualidade e quantidade de forragem disponível para o pastejo. Como consequência, os bezerros não conseguem manifestar o seu potencial genético produtivo. Assim, o desempenho é melhorado quando os animais recebem suplementos múltiplos (VALENTE et al., 2012), especialmente quando se utiliza suplementos proteicos (VALENTE et al., 2011a).
A suplementação de bovinos em pastejo é uma estratégia para aumento de produtividade dos sistemas de produção de carne bovina. Em sistemas de criação mais intensificados, nos quais se visa a redução da idade à primeira cria, é fundamental o uso de tecnologias que permitam às bezerras a otimização do ganho de peso, em todas as fases do ciclo produtivo, inclusive durante a amamentação. O creep feeding propicia maior peso dos animais ao desmame, consequentemente, reduz a fase de recria (PAULINO, 1999).

$\mathrm{O}$ uso de fontes proteicas alternativas que não comprometam o desempenho animal constitui opção viável para reduzir os custos com a suplementação, permitindo a otimização da produção animal.

O farelo do algodão com $38 \%$ de proteína bruta (PB) é um co-produto agroindustrial que tem sido utilizado com o objetivo de reduzir o uso de farelo de soja em suplementos múltiplos para bovinos, 
e embora apresente menores teores de energia e proteína, é caracterizado pelo seu maior teor de proteína não -degradável no rúmen.

Desta forma, objetivou-se avaliar o desempenho produtivo e nutricional de bezerras em creepfeeding, recebendo mistura mineral ou suplementos múltiplos; e a produção de leite, o consumo e a digestibilidade da forragem consumida por vacas de corte, em pastagens de capim-braquiária, durante o período de transição águas-seca.

\section{Material e Métodos}

Animais, delineamento experimental e suplementos

O experimento foi conduzido nas dependências do Setor de Bovinocultura de Corte da Universidade Federal de Viçosa, localizado no município de Viçosa-MG (20 $45^{\prime}$ 'S e $\left.42^{\circ} 52^{\prime} \mathrm{W}\right)$, entre os meses de março a julho de 2010, referente ao período de transição águas-seca. A área experimental está localizada em região montanhosa com $670 \mathrm{~m}$ de altitude e apresenta precipitação anual de $1300 \mathrm{~mm}$. O experimento teve duração de 90 dias, divididos em três períodos experimentais com 30 dias cada.

Foram utilizadas 48 bezerras com, no mínimo, $50 \%$ de sangue Nelore, e idade e pesos médios iniciais, de 5 meses e 125,5 $\pm 1,34 \mathrm{~kg}$, respectivamente, acompanhadas de suas respectivas mães com idade e peso médios iniciais de 6 anos e
$435,2 \pm 10,3 \mathrm{~kg}$, respectivamente.

Foi destinada aos animais uma área experimental com 35 hectares, sendo esta constituída por cinco piquetes de 7,0 ha, cobertos uniformemente com a gramínea Uruchloa decumbens, providos de bebedouros e cochos, sendo estes cobertos e com acesso pelos dois lados.

O delineamento experimental foi o inteiramente casualizado, com cinco tratamentos, sendo três tratamentos com dez repetições e dois tratamentos com nove repetições.

Foram avaliados quatro suplementos (Tabela 1) com aproximadamente $25 \%$ de proteína. Os suplementos foram a base de substituição progressiva do farelo de soja pelo farelo de algodão $38 \%$ mais uma mistura de uréia/sulfato de amônio, aos níveis de 0, 33, 67 e 100\% da fonte proteica, para os tratamentos $\mathrm{FA}_{0}, \mathrm{FA}_{33}, \mathrm{FA}_{67}$ e $\mathrm{FA}_{100}$, respectivamente, mais um grupo controle nos quais os animais receberam apenas mistura mineral (MM) ad libitum. Os suplementos foram fornecidos na quantidade de $0,5 \mathrm{~kg}$ por animal por dia. Adicionouse quantidade mínima de uréia aos suplementos que continham farelo de algodão $38 \%$, afim de manter os suplementos isoprotéicos. As vacas, além da mistura mineral à vontade, receberam $100 \mathrm{~g} /$ dia de fubá de milho como forma de estimular a procura e o maior tempo de permanência próximo dos cochos e, assim, garantir o melhor consumo de suplemento pelas bezerras. 
Tabela 1. Composição do suplemento, com base na matéria natural.

\begin{tabular}{|c|c|c|c|c|c|}
\hline \multirow{2}{*}{ Item } & \multicolumn{5}{|c|}{ Suplementos } \\
\hline & $\mathrm{MM}$ & $\mathrm{FA}_{0}$ & $\mathrm{FA}_{33}$ & $\mathrm{FA}_{67}$ & $\mathrm{FA}_{100}$ \\
\hline \multicolumn{6}{|l|}{ Ingredientes } \\
\hline Mistura mineral $^{1}(\mathrm{~g} / \mathrm{kg})$ & 1000 & 60 & 60 & 60 & 60 \\
\hline Sorgo $(g / k g)$ & --- & 215 & 215 & 215 & 215 \\
\hline Milho (g/kg) & --- & 215 & 215 & 215 & 215 \\
\hline Farelo de Algodão (38\% PB) (g/kg) & & & 165 & 335 & 500 \\
\hline Farelo de Soja (g/kg) & --- & 500 & 335 & 165 & \\
\hline Uréia/SA (g/kg) & & 0 & 3 & 5 & 10 \\
\hline Farelo de trigo $(\mathrm{g} / \mathrm{kg})$ & --- & 10 & 7 & 5 & 0 \\
\hline
\end{tabular}

${ }^{1}$ Composição percentual: fosfato bicálcico, 50,00; cloreto de sódio, 47,775; sulfato de zinco, 1,40; sulfato de cobre, 0,70; sulfato de cobalto, 0,05; iodato de potássio, 0,05 e selenito de sódio 0,025 .

MM: Mistura mineral; $\mathrm{FA}_{0}$ : sem inclusão de farelo de algodão; $\mathrm{FA}_{33}$ : substituição de $33 \%$ do farelo de soja por farelo de algodão; $\mathrm{FA}_{67}$ : substituição de $67 \%$ do farelo de soja por farelo de algodão e $\mathrm{FA}_{100}$ : substituição de $100 \%$ do farelo de soja por farelo de algodão.

Fonte: Elaboração dos autores.

Os suplementos foram fornecidos diariamente, às $10 \mathrm{~h} 00$, em comedouro conjunto, com dois metros de comprimento, para permitir o acesso simultâneo dos animais. A água foi disponibilizada ad libitum durante todo o experimento.

Ao início do experimento, todos os animais foram submetidos ao controle de ecto e endoparasitas e durante o período experimental, quando necessário.

Os animais foram pesados no início do experimento após jejum de 14 horas e em seguida, foram aleatoriamente distribuídos nos diferentes tratamentos, sendo que cada animal representou uma unidade experimental.A variação do escore corporal das vacas, durante o período experimental, foi determinada pela diferença entre o escore de condição corporal final e inicial. Foi utilizada a escala de pontuação de 1 a 9 pontos, recomendada pelo NRC (1996). A pontuação foi obtida por três avaliadores devidamente treinados e a atribuição das notas ocorreu de forma independente entre os avaliadores.

Para estimação da produção média de leite das vacas foram realizadas três amostragens da produção leiteira, 25, 50 e 75 dias após o início do experimento. As vacas foram separadas de suas crias às 18 h00 e permaneceram no piquete, sendo ordenhadas às 6 h00 do dia seguinte. O horário em que cada vaca foi ordenhada foi registrado e posteriormente converteu-se a produção de leite para uma produção em 24 horas. A ordenha foi executada manualmente por um funcionário treinado. A secreção do leite foi estimulada com a aplicação de $2 \mathrm{~mL}$ de ocitocina (10 UI/mL; Ocitovet ${ }^{\circledR}$, Brasil) na artéria mamária, iniciando a ordenha imediatamente após a aplicação da ocitocina. Foram retiradas amostras de leite para análise do teor de proteína, gordura, lactose, fósforo e cálcio.

A cada quatorze dias os animais foram rotacionados entre os piquetes, visando o controle de possíveis efeitos de piquetes sobre os tratamentos (disponibilidade de pasto, localização da aguada e cocho, relevo, sombreamento e outros .

O ganho médio diário de peso dos animais em cada fase experimental foi estimado pela diferença entre o peso final e o inicial, dividido pelo número de dias experimentais.

\section{Procedimentos experimentais e amostragens}

A amostragem para avaliação qualitativa do pasto consumido pelos animais foi realizada via 
simulação manual de pastejo a cada 15 dias. Essa amostra foi pesada e levada imediatamente à estufa com circulação forçada de ar a $60^{\circ} \mathrm{C}$ por 72 horas e moída em moinho de facas $(1 \mathrm{~mm})$.

No décimo quinto dia de cada período experimental foi realizada coleta do pasto para quantificação da quantidade de matéria seca e de matéria seca potencialmente digestível (MSpd), através do corte rente ao solo em quatro áreas delimitadas por um quadrado metálico de $0,5 \times 0,5$ $\mathrm{m}$, selecionados aleatoriamente em cada piquete experimental. As amostra foram pesadas e levadas imediatamente à estufa com circulação forçada de ar a $60^{\circ} \mathrm{C}$ por 72 horas.

A MSpd foi estimada segundo a seguinte equação (PAULINO; DETMANN; VALADARES FILHO, 2008):

$\mathrm{MSpd}=0,98 \times(100-\mathrm{FDNcp})+(\mathrm{FDNcp}-\mathrm{FDNi})$

Para avaliação das características nutricionais, bem como das bezerras e das vacas, a partir do $40^{\circ}$ dia do período experimental foi realizado um ensaio com duração de nove dias. Utilizou-se o método de três indicadores. Para estimar a excreção fecal, foi fornecido aos animais o indicador externo óxido crômico $\left(\mathrm{Cr}_{2} \mathrm{O}_{3}\right)$, acondicionado em cartuchos de papel (DETMANN et al., 2001), correspondente a $10 \mathrm{~g}$ por bezerra/dia e $20 \mathrm{~g}$ por vaca/dia, aplicado com auxílio de uma sonda metálica diretamente no esôfago, sempre às 10h00. Para estimar o consumo individual de suplemento pelas bezerras foi utilizado o dióxido de titânio $\left(\mathrm{TiO}_{2}\right)$, fornecido via suplemento na proporção de $10 \mathrm{~g}$ de indicador $/ \mathrm{kg}$ de suplemento (TITGEMEYER et al., 2001). Para estimar o consumo de MS de pasto foi utilizado como indicador interno a FDNi (DETMANN et al., 2001).

Dos nove dias do ensaio, seis foram destinados à adaptação dos animais ao $\mathrm{Cr}_{2} \mathrm{O}_{3}$ e ao $\mathrm{TiO}_{2}$. Nos últimos três dias foram realizadas coletas de fezes em horários diferenciados, às 15h00, $11 \mathrm{~h} 00$ e às $7 \mathrm{~h} 00$, respectivamente. As amostras de fezes foram coletadas imediatamente após a defecação ou diretamente no reto dos animais, em quantidades aproximadas de 200 g, sendo identificadas por animal e secas em estufa com circulação forçada de ar $\left(60^{\circ} \mathrm{C} / 72\right.$ horas $)$ e após a secagem, moídas em moinho de facas $(1 \mathrm{~mm})$. No quinto dia do ensaio foi realizada uma simulação manual de pastejo, em cada piquete separadamente, sendo estas amostras usadas para a estimação do consumo e dos coeficientes de digestibilidade.

\section{Análises químicas}

Nas amostras de forragem obtidas via simulação manual do pastejo e dos concentrados foram quantificados os teores de matéria seca (MS); matéria mineral $(\mathrm{MM})$; proteína bruta $(\mathrm{PB})$, extrato etéreo (EE) e lignina, segundo Silva e Queiroz (2002). A fibra em detergente neutro (FDNcp), foi determinada segundo Mertens (2002), utilizandose $\alpha$-amilase termoestável e omitindo-se o uso de sulfito de sódio, sendo realizadas correções para proteína e cinzas na FDN. Quantificou-se o teor de nitrogênio insolúvel em detergente neutro (NIDN) e o teor de fibra em detergente ácido (FDA) conforme as recomendações de Van Soest e Robertson (1985), com correções para proteína e cinzas. A fibra em detergente neutro indigestível (FDNi), foi determinada de acordo com Valente et al. (2011b), obtida após a incubação em sacos (F57 Ankom $^{\circledR}$ ) in situ por 288 horas. Nas amostras de forragem destinadas ao cálculo da massa de MS e MSpd foram quantificados os teores de MS; FDNcp e FDNi, conforme descrito anteriormente.

Os carboidratos não fibrosos dos suplementos foram estimados segundo recomendações de Hall e Akinyode (2000), utilizando-se a seguinte equação:

$C N F c p=100-[(\% P B-\% P B U+\%$ de uréia $)+$ $\% F D N c p+\% E E+\%$ de cinzas)

onde: $\mathrm{PBU}=\mathrm{PB}$ no suplemento advinda da uréia 
A composição do suplemento e da forragem obtida é apresentada na Tabela 2.

Foi elaborada uma amostra composta de fezes com base no peso seco ao ar, por animal, dos três dias de coleta, as quais foram armazenadas em potes plásticos, devidamente identificadas e posteriormente analisadas quanto aos teores de cromo, por espectrofotometria de absorção atômica (WILLIANS; DAVID; IISMA, 1962); e de dióxido de titânio por colorimetria (TITGEMEYER et al., 2001). Avaliaram-se também os teores de MS; PB; EE; FDNcp; FDNi e MM, conforme descrito anteriormente.

Tabela 2. Composição química dos suplementos e da forragem utilizados no experimento.

\begin{tabular}{|c|c|c|c|c|c|c|}
\hline \multirow{2}{*}{ Item $^{1}$} & \multicolumn{4}{|c|}{ Suplementos } & \multirow[b]{2}{*}{ Forragem $^{2}$} & \multirow[b]{2}{*}{ Forragem $^{3}$} \\
\hline & $\mathrm{FA}_{0}$ & $\mathrm{FA}_{33}$ & $\mathrm{FA}_{67}$ & $\mathrm{FA}_{100}$ & & \\
\hline Matéria seca $(\mathrm{g} / \mathrm{kg}$ de $\mathrm{MN})$ & 944,0 & 956,0 & 957,0 & 958,9 & $309,9 \pm 2,46$ & $262,8 \pm 0,91$ \\
\hline Matéria orgânica (g/kg de MS) & 905,3 & 906,8 & 908,7 & 910,4 & $931,8 \pm 0,18$ & $935,6 \pm 0,11$ \\
\hline Proteína bruta (g/kg de MS) & 270,0 & 257,6 & 257,4 & 257,9 & $74,6 \pm 0,47$ & $71,4 \pm 0,37$ \\
\hline NIDN (g/kg de NT) & 258,5 & 266,7 & 273,5 & 281,1 & $262,4 \pm 1,31$ & $249,6 \pm 1,67$ \\
\hline Extrato etéreo ( $\mathrm{g} / \mathrm{kg}$ de MS) & 16,5 & 16,7 & 16,9 & 17,1 & $16,1 \pm 0,05$ & $12,5 \pm 0,03$ \\
\hline $\operatorname{FDNcp}(\mathrm{g} / \mathrm{kg}$ de MS $)$ & 108,8 & 156,5 & 203,8 & 249,8 & $632,9 \pm 1,46$ & $659,3 \pm 0,43$ \\
\hline Carboidratos não fibrosos ( $\mathrm{g} / \mathrm{kg}$ de $\mathrm{MS}$ ) & 510,0 & 456,0 & 438,1 & 400,6 & $208,2 \pm 0,20$ & $192,4 \pm 0,13$ \\
\hline FDAcp (g/kg de MS) & 69,1 & 88,9 & 109,2 & 129,1 & $310,4 \pm 1,21$ & $307,7 \pm 1,14$ \\
\hline FDNi (g/kg de MS) & 8,1 & 27,7 & 47,6 & 66,8 & $233,3 \pm 0,55$ & $179,5 \pm 0,75$ \\
\hline $\operatorname{Lignina}(\mathrm{g} / \mathrm{kg}$ de MS) & 30,1 & 39 & 48,1 & 57,1 & $54,3 \pm 0,28$ & $49,4 \pm 0,38$ \\
\hline
\end{tabular}

${ }^{1} \mathrm{MN}$ : Matéria natural; MS: matéria seca; NT: nitrogênio total; NIDN - nitrogênio insolúvel em detergente neutro; FDNcp - fibra em detergente neutro corrigida para cinzas e proteína; FDAcp - fibra em detergente ácido corrigida para cinzas e proteína; FDNi - fibra em detergente neutro indigestível. ${ }^{2}$ Média das amostras obtidas por simulação manual do pastejo durante todo o período experimental. ${ }^{3}$ Média das amostras obtidas durante o ensaio para avaliação das características nutricionais. FA : sem inclusão de farelo de algodão; $\mathrm{FA}_{33}$ : substituição de $33 \%$ do farelo de soja por farelo de algodão; $\mathrm{FA}_{67}$ : substituição de $67 \%$ do farelo de soja por farelo de algodão e $\mathrm{FA}_{100}$ : substituição de $100 \%$ do farelo de soja por farelo de algodão.

Fonte: Elaboração dos autores.

A excreção de matéria seca fecal foi estimada utilizando-se o indicador óxido crômico, sendo estimada pela razão entre a quantidade do indicador fornecido e sua concentração nas fezes.

A estimativa do consumo individual de suplemento pelas bezerras foi obtida através da seguinte equação:

\section{CISup $=((E F x C I F i) / I F G) \times \operatorname{SupFG}$}

em que: CISup = consumo individual de suplemento $(\mathrm{kg} / \mathrm{dia}) ; \mathrm{EF}$ = excreção fecal em kg/ dia; CIFi = concentração do indicador nas fezes do animal $(\mathrm{kg} / \mathrm{kg}) ; \mathrm{IFG}=$ indicador presente no suplemento fornecido ao grupo $(\mathrm{kg} / \mathrm{dia}) ; \mathrm{SupFG}=$ quantidade de suplemento fornecida ao grupo de animais $(\mathrm{kg} / \mathrm{dia})$.

A estimação do consumo voluntário de matéria seca foi realizada empregando-se como indicador interno a FDN indigestível, conforme a equação:

\section{CMS $(\mathrm{kg} / \mathrm{dia})=\{[($ EFxCIF $)-\mathrm{IS}] / \mathrm{CIFO}\}+\mathrm{CMSS}$ $+\mathrm{CMSL}$}

em que: $\mathrm{CIF}=$ concentração do indicador nas fezes $(\mathrm{kg} / \mathrm{kg})$; CIFO = concentração do indicador na forragem $(\mathrm{kg} / \mathrm{kg}) ; \mathrm{CMSS}=$ consumo de matéria seca de suplemento $(\mathrm{kg} / \mathrm{dia}) ; \mathrm{EF}=$ excreção fecal $(\mathrm{kg} / \mathrm{dia})$; IS = consumo de indicador a partir do suplemento $(\mathrm{kg})$; e $\mathrm{CMSL}=$ Consumo de matéria seca de leite $(\mathrm{kg} / \mathrm{dia})$. 
Para calcular o consumo de MS pelas vacas, utilizou-se a equação acima desconsiderando-se o CMSS e CMSL.

\section{Análises estatísticas}

Para todas as análise estatísticas referente as variáveis avaliadas nas bezerras utilizou-se o PROC MIXED do SAS (Statistical Analysis System, versão 9.2). Para todos os procedimentos estatísticos foi adotado $\alpha=0,10$. As comparações entre as médias observadas foram realizadas por meio da decomposição da soma de quadrados para tratamentos em contrastes ortogonais relativos à comparação entre suplementação e nãosuplementação, e o efeito linear e quadrático para os níveis de substituição do farelo de soja pelo farelo de algodão (38\% PB), utilizou-se o peso corporal inicial das bezerras como co-variável.

Os tratamentos aplicados às bezerras não influenciaram as variáveis avaliadas nas matrizes, sendo assim, realizou-se uma análise descritiva para as variáveis avaliadas nas matrizes.

\section{Resultados e Discussão}

O desempenho do animal em pastejo está diretamente relacionado à oferta de forragem e esta influencia no comportamento de pastejo, interferindo na qualidade e quantidade de nutrientes e atributos nutricionais consumidos pelos animais, o que é determinante do desempenho animal em pastejo.

Para entender o sistema de criação de bovinos em pastejo, deve-se buscar entendimento das partes que o compõem (animal, planta e meio), assim como as suas interações. Visando expressar melhor essas inter-relações, foi elaborado o conceito de matéria seca potencialmente digestível (MSpd) (PAULINO et al., 2004), que segundo Paulino, Detmann e Valadares Filho (2008) constitui medida integradora dos aspectos quantitativos e qualitativos do pasto, o que permite maior precisão na avaliação real da capacidade de suporte e desempenho animal na área utilizada.

As massas médias de MS e MSpd durante o período experimental foram de 4099,7 e 2790,0 kg/ ha, respectivamente, o que representou uma massa média de MSpd igual 130,7 g/kg de PC. O capimbraquiária obtido via simulação manual do pastejo apresentou teor médio de PB de 74,6 g de PB/kg de MS.

A oferta de MSpd expressa em função do peso corporal(PC), remete a ideia quantitativa equalitativa da forragem disponível momentaneamente ao animal, independente da taxa de lotação. Paulino et al. (2004) visando associar produção por animal e por área, sugeriram o fornecimento entre 4 e 5\% do PC em MSpd (entre 40 e $50 \mathrm{~g}$ de MSpd/kg de PC), de pasto para um desempenho animal satisfatório dos animais em regime de pastejo. Neste trabalho a massa média de MSpd foi de 130,7 g/ $\mathrm{kg}$ de $\mathrm{PC}$, valor acima do recomendado por este autor, demonstrando que a quantidade de forragem não comprometeu o desempenho animal.

O capim-braquiária obtido via simulação manual de pastejo apresentou teor médio de 74,6 $\mathrm{g}$ de $\mathrm{PB} / \mathrm{kg}$ de MS (Tabela 2), estando dentro do valor mínimo de $7-8 \%$ de $\mathrm{PB}$ na dieta basal relatado por Lazzarini et al. (2009) como necessário para que haja adequado aproveitamento da fibra em detergente neutro (FDN) da forragem basal, que é a principal fonte de energia para os animais criados a pasto. Porém, este valor esteve abaixo dos $10 \%$ citados por Sampaio et al. (2009) como nível que otimiza a utilização de substratos energéticos da forragem, o que justifica a suplementação com compostos nitrogenados para otimizar a utilização da forragem e consequentemente o desempenho animal. Este fato pode ser comprovado pelo desempenho superior $(\mathrm{P}<0,10)$ das bezerras que receberam suplementos múltiplos em relação às bezerras que receberam apenas mistura mineral (Tabela 3). 
O ganho médio diário das bezerras (Tabela 3) foi de 687,$8 ; 733,2 ; 820,0 ; 760,6$ e $764,5 \mathrm{~g} / \mathrm{dia}$ para os tratamentos $\mathrm{MM}, \mathrm{FA}_{0}, \mathrm{FA}_{33}, \mathrm{FA}_{67}$ e $\mathrm{FA}_{100}$, respectivamente.

Tabela 3. Médias, desvio padrão e indicativos de significância para peso corporal inicial, peso corporal final e ganho médio diário para as bezerras suplementados e não suplementadas durante a transição águas-seca.

\begin{tabular}{|c|c|c|c|c|c|c|c|c|c|}
\hline \multirow[b]{2}{*}{ Item } & \multicolumn{5}{|c|}{ Suplementos } & \multirow{2}{*}{$\begin{array}{l}\text { Desvio } \\
\text { Padrão }\end{array}$} & \multicolumn{3}{|c|}{ Valor $-\mathrm{P}^{1}$} \\
\hline & $\mathrm{MM}$ & $\mathrm{FA}_{0}$ & $\mathrm{FA}_{33}$ & $\mathrm{FA}_{67}$ & $\mathrm{FA}_{100}$ & & $\mathrm{CO}$ & $\mathrm{L}$ & $\mathrm{Q}$ \\
\hline $\begin{array}{l}\text { Peso Corporal Inicial } \\
(\mathrm{kg})\end{array}$ & 120,6 & 124,9 & 125,1 & 130,1 & 126,5 & & & & \\
\hline Peso Corporal Final (kg) & 187,6 & 191,5 & 199,3 & 193,6 & 194,2 & 8,54 & 0,0339 & 0,8451 & 0,1968 \\
\hline $\begin{array}{l}\text { Ganho médio diário (g/ } \\
\text { dia) }\end{array}$ & 687,8 & 733,2 & 820,0 & 760,6 & 764,5 & 0,095 & 0,0259 & 0,8010 & 0,1845 \\
\hline
\end{tabular}

${ }^{1}$ Indicativos de significância para contraste entre animais suplementados e não suplementados (CO) e para efeito de ordem linear (L) e quadrática (Q) do nível de substituição do farelo de soja pelo farelo de algodão (38\% PB) nos suplementos. MM: Mistura mineral; $\mathrm{FA}_{0}$ : sem inclusão de farelo de algodão; $\mathrm{FA}_{33}$ : substituição de $33 \%$ do farelo de soja por farelo de algodão; FA 6 : substituição de $67 \%$ do farelo de soja por farelo de algodão e $\mathrm{FA}_{100}$ : substituição de $100 \%$ do farelo de soja por farelo de algodão.

Fonte: Elaboração dos autores.

Este resultado pode ser atribuído ao maior consumo de compostos nitrogenados (Tabela 4) pelos animais suplementados com suplementos múltiplos, o que pode ter apresentado efeito benéfico sobre o ambiente ruminal, propiciando melhor uso da dieta consumida pelos animais suplementados e consequentemente maior ganho de peso. Tal resultado reafirma a importância da suplementação de bezerros lactentes com o objetivo de se complementar a ingestão de nutrientes e atributos nutricionais e otimizar o desempenho produtivo destes animais, proporcionando maiores peso a desmama, contribuindo para reduzir a duração da fase de recria, pois, em regiões tropicais, o consumo de leite e forragem não é suficiente para permitir aos bezerros expressarem o seu potencial genético (VALENTE et al., 2012).

Entre os níveis de substituição do farelo de soja pelo farelo de algodão ( $38 \%$ PB) não houve diferença no ganho médio diário (GMD) das bezerras. A substituição do farelo de soja por farelo de algodão (38\% PB) não prejudicou o desempenho dos animais.

A avaliação visual do escore de condição corporal (ECC) constitui prática que busca entender a composição corporal do animal adulto em termos de percentual de gordura. Embora, seja considerada uma medida subjetiva, o ECC é uma importante ferramenta utilizada nos sistemas de produção de bovinos, por levar em consideração o acúmulo de reservas corporais das quais a fêmea dispõe para mobilizar durante a fase de aleitamento (OLIVEIRA et al., 2006). Neste estudo não houve diferenças significativas $(\mathrm{P}>0,10)$ para o peso corporal final, ganho médio diário e escore de condição corporal final (Tabela 6) das vacas em função dos tratamentos aplicados as suas bezerras.

$\mathrm{O}$ número de mamadas diárias influencia na produção de leite e no desgaste físico da mãe (KRESS DOORNBOS; ANDERSON, 1990), de modo que o maior número de mamadas ao longo do dia poderia levar a vaca a apresentar maior produção de leite em resposta ao maior estímulo e, consequentemente, maior desgaste físico. Contudo, de forma similar aos resultados encontrados neste trabalho, Gelvin et al. (2004) e Valente et al. (2012) não encontraram diferenças na produção de leite entre vacas que tiveram suas crias suplementadas ou que não receberam suplementos múltiplos. A 
quantidade de suplemento ofertado às bezerras, não foi suficiente para alterar o comportamento da amamentação e consequentemente a produção de leite, a condição corporal e o peso corporal final das vacas. Sendo assim, a produção de leite das vacas não influenciou o desempenho das bezerras, sendo as diferenças observadas no GMD devido apenas ao fornecimento de suplemento múltiplo.
$\mathrm{Na}$ Tabela 4 estão apresentadas as estimativas de consumo pelas bezerras. Os consumos em $\mathrm{kg}$ / dia de MS, MO, CNF e NDT foram maiores para as bezerras suplementadas com suplementos múltiplos do que para as bezerras que receberam apenas mistura mineral. O consumo de suplemento múltiplo foi de 440, 420, 480 e $430 \mathrm{~g} /$ dia, respectivamente, pelos animais dos tratamentos $\mathrm{FA}_{0}, \mathrm{FA}_{33}, \mathrm{FA}_{67}$ e FA ${ }_{100}$.

Tabela 4. Médias, desvio padrão e indicativos de significância para o consumo de componentes da dieta pelas bezerras suplementadas e não suplementadas com suplementos múltiplos.

\begin{tabular}{|c|c|c|c|c|c|c|c|c|c|}
\hline \multirow{2}{*}{ Item $^{1}$} & \multicolumn{5}{|c|}{ Suplementos } & \multirow{2}{*}{$\begin{array}{l}\text { Desvio } \\
\text { padrão }\end{array}$} & \multicolumn{3}{|c|}{ Valor - $\mathrm{P}^{2}$} \\
\hline & MM & $\mathrm{FA}_{0}$ & $\mathrm{FA}_{33}$ & $\mathrm{FA}_{67}$ & $\mathrm{FA}_{100}$ & & $\mathrm{CO}$ & $\mathrm{L}$ & $\mathrm{Q}$ \\
\hline & \multicolumn{9}{|c|}{$\mathrm{kg} / \mathrm{dia}$} \\
\hline Matéria seca & 2,97 & 3,36 & 3,24 & 3,14 & 3,15 & 0,37 & 0,0728 & 0,1700 & 0,5711 \\
\hline Matéria seca de forragem & 2,10 & 2,02 & 1,85 & 1,74 & 1,86 & 0,42 & 0,1429 & 0,3320 & 0,3001 \\
\hline Matéria seca de leite & 0,86 & 0,90 & 0,96 & 0,92 & 0,86 & 0,20 & 0,5457 & 0,5228 & 0,3692 \\
\hline Matéria orgânica & 2,80 & 3,17 & 3,06 & 3,02 & 3,00 & 0,34 & 0,0669 & 0,1700 & 0,5649 \\
\hline Matéria orgânica de forragem & 1,97 & 1,89 & 1,74 & 1,62 & 1,74 & 0,39 & 0,1285 & 0,3264 & 0,2902 \\
\hline Proteína bruta & 0,36 & 0,46 & 0,45 & 0,46 & 0,48 & 0,04 & $<0,0001$ & 0,2694 & 0,2896 \\
\hline Extrato etéreo & 0,33 & 0,33 & 0,35 & 0,32 & 0,30 & 0,06 & 0,8735 & 0,1876 & 0,1860 \\
\hline FDNcp & 1,35 & 1,37 & 1,28 & 1,22 & 1,32 & 0,27 & 0,6338 & 0,5721 & 0,2727 \\
\hline Carboidratos não fibrosos ${ }^{3}$ & 0,75 & 1,01 & 0,97 & 0,95 & 0,87 & 0,08 & $<0,0001$ & 0,3730 & 0,0751 \\
\hline Matéria seca digerida ${ }^{4}$ & 2,16 & 2,54 & 2,48 & 2,38 & 2,37 & 0,24 & 0,0026 & 0,0853 & 0,8036 \\
\hline Fibra em detergente neutro digerida ${ }^{5}$ & 0,99 & 1,03 & 0,96 & 0,87 & 0,80 & 0,24 & 0,4132 & 0,0322 & 0,9909 \\
\hline Nutrientes digestíveis totais & 2,49 & 2,81 & 2,80 & 2,66 & 2,75 & 0,27 & 0,0146 & 0,4069 & 0,5589 \\
\hline \multirow[t]{2}{*}{ FDNi } & 0,37 & 0,37 & 0,35 & 0,35 & 0,38 & 0,07 & 0,7206 & 0,6935 & 0,2988 \\
\hline & \multicolumn{9}{|c|}{$\mathrm{g} / \mathrm{kg}$ de $\mathrm{PC}$} \\
\hline Matéria seca ${ }^{6}$ & 18,71 & 21,28 & 19,95 & 19,42 & 19,13 & 2,2 & 0,1404 & 0,0333 & 0,4733 \\
\hline Matéria seca de forragem & 13,15 & 12,83 & 11,28 & 10,73 & 11,20 & 2,4 & 0,0739 & 0,1211 & 0,2013 \\
\hline Matéria orgânica ${ }^{7}$ & 17,66 & 20,11 & 18,88 & 18,35 & 18,11 & 2,0 & 0,1312 & 0,0332 & 0,4696 \\
\hline Matéria orgânica de forragem & 12,35 & 12,00 & 10,56 & 10,00 & 10,48 & 2,2 & 0,0647 & 0,1184 & 0,1939 \\
\hline FDNcp & 8,45 & 8,76 & 7,81 & 7,52 & 7,98 & 1,6 & 0,4692 & 0,2526 & 0,1796 \\
\hline $\mathrm{FDNi}^{8}$ & 2,36 & 2,64 & 2,11 & 2,06 & 2,19 & 0,4 & 0,4937 & 0,0265 & 0,0185 \\
\hline
\end{tabular}

${ }^{1}$ FDNcp: Fibra em detergente neutro corrigida para cinzas e proteínas. FDNi: fibra em detergente neutro indigestível. ${ }^{2}$ Indicativos de significância para contraste entre animais suplementados e não suplementados (CO) e para efeito de ordem linear (L) e quadrática (Q) do nível de substituição do farelo de soja pelo farelo de algodão 38\% nos suplementos. MM: Mistura mineral; FA: sem inclusão de farelo de algodão; $\mathrm{FA}_{33}$ : substituição de $33 \%$ do farelo de soja por farelo de algodão; $\mathrm{FA}_{67}$ : substituição de $67 \%$ do farelo de soja por farelo de algodão e $\mathrm{FA}_{100}$ : substituição de $100 \%$ do farelo de soja por farelo de algodão. ${ }^{3} \hat{\mathrm{Y}}=0,9743-0,0021 \mathrm{X}+0,00002$ $\mathrm{x}^{2}\left(\mathrm{R}^{2}=0,9457\right) \cdot{ }^{4} \hat{\mathrm{Y}}=2,5384-0,00157 \mathrm{x}\left(\mathrm{R}^{2}=0,9990\right) .{ }^{5} \hat{\mathrm{Y}}=1,0336-0,0021 \mathrm{x}\left(\mathrm{R}^{2}=0,9805\right)$.

${ }^{6} \hat{Y}=21,7400-0,7367 x\left(R^{2}=0,8813\right) .{ }^{7} \hat{Y}=20,5501-0,6922 x\left(R^{2}=0,8812\right) .8 \hat{Y}=3,4466-0,9851 x+0,1690 x^{2}\left(R^{2}=0,9702\right)$.

Fonte: Elaboração dos autores.

Quando expresso em $\mathrm{g} / \mathrm{kg}$ de peso corporal, os consumos de MS de forragem e MO de forragem foram maiores nos animais não suplementados com suplementos múltiplos e que receberam apenas 
mistura mineral.

Houve efeito da substituição do farelo de soja pelo farelo de algodão (38\% PB) nos suplementos sobre o consumo em $\mathrm{kg} /$ dia de $\mathrm{CNF}$, que apresentou efeito quadrático, e MSD e FDND que apresentaram efeito linear decrescente.

A suplementação múltipla aumentou o consumo (Tabela 4) em kg/dia de MS, MO, PB, CNF, MSD e NDT. A diferença no consumo foi provavelmente devido ao consumo de matéria seca de suplemento pois, não houve diferença no consumo de matéria seca de forragem em $\mathrm{kg} /$ dia entre as bezerras suplementadas com suplementos múltiplos e suplementadas apenas com mistura mineral.

Os consumos de MS de forragem (MSF) e MO de forragem (MOF) em $\mathrm{g} / \mathrm{kg}$ de peso corporal foram maiores em bezerras não suplementadas, provavelmente devido ao efeito substitutivo, visto que o consumo de matéria seca de forragem pelos animais suplementados foi numericamente inferior.

Entre os níveis de substituição do farelo de soja pelo farelo de algodão (38\% PB) observou-se efeito linear decrescente sobre o consumo em $\mathrm{kg}$ / dia de fibra em detergente neutro digerida (FDND) e MSD $(\mathrm{P}<0,10)$, provavelmente devido a menor degradabilidade do farelo de algodão (38\% PB) quando comparado com o farelo de soja. Observouse efeito quadrático do nível de farelo de algodão (38\% PB) nos suplementos sobre o consumo de CNF e FDNi em g/kg de PC.

A mensuração da massa ingerida efetivamente digerida permite integraros efeitos da suplementação das bezerras sobre o consumo e digestibilidade. Neste estudo observou-se efeito da suplementação múltipla sobre o consumo de MS e sobre a digestibilidade da MS (Tabela 5), o que elevou o consumo de MSD pelas bezerras que receberam suplementos múltiplos. A maior digestibilidade da MS nos animais que receberam suplementos múltiplos, pode ser devida em parte, à maior ingestão de compostos nutricionais de fácil digestão, ao invés do aumento da digestibilidade do pasto, visto que não houve alteração da digestibilidade total da FDNcp $(\mathrm{P}>0,10)$ em resposta ao consumo de suplemento.

Houve efeito da suplementação múltipla $(\mathrm{P}<0,10)$ sobre a ingestão de nutrientes digestíveis totais (NDT) em kg/dia. Os incrementos causados no teor de NDT da dieta com a suplementação parecem refletir a ampliação nos coeficientes de digestibilidade da PB e CNF, não havendo, portanto, aumento significativo na extração de energia a partir da FDNcp. Este comportamento é reforçado considerando-se que a suplementação tenha elevado o consumo de NDT, sem, contudo afetar o consumo de FDNcp digerida $(\mathrm{P}>0,10)$.

Quando o consumo de componentes da dieta pelas bezerras foi avaliado como fração do peso corporal, verificou-se efeito linear decrescente nos consumos de MS e MO (Tabela 4), evidenciando que dietas com maiores níveis de farelo de algodão $(38 \%$ PB) proporcionam menores médias de consumo, quando comparadas com dietas contendo farelo de soja.

A avaliação do consumo de MS de leite não apresentou diferença significativa $(\mathrm{P}>0,10)$, confirmando que a produção de leite das mães foi semelhante nos diferentes grupos de animais, não sendo, portanto, um fator que interferiria na diferença de desempenho entre os animais.

De acordo com os dados do Valadares Filho et al. (2010), bezerros de corte com peso corporal de $125 \mathrm{~kg}$, com GMD igual a 750 gramas apresentam exigência de $1,78 \mathrm{~kg}$ de NDT/dia. Neste estudo o consumo de NDT pelas bezerras em $\mathrm{kg} / \mathrm{dia}$ foi de 2,48; 2,814; 2,802; 2,661 e 2,750; para os suplementos MM, FA0, FA33, FA67 e FA100, respectivamente. Em relação à exigência de proteína bruta para bezerros com $125 \mathrm{~kg}$ de peso corporal e GMD igual a 750 gramas a exigência é igual a 467,1 $\mathrm{g} /$ dia. O consumo de PB pelas bezerras em $\mathrm{g} /$ dia foi de $362 ; 461 ; 454 ; 466$ e 483; para os tratamentos MM, FA0, FA33, FA67 e FA100, respectivamente. Sendo assim, apesar do consumo de NDT ter sido 
acima da exigência para ganho de $750 \mathrm{~g} / \mathrm{dia}$ em todos os tratamentos, o consumo de PB limitou o desempenho dos animais que receberam apenas suplementação mineral, não permitindo que esses animais tivessem um GMD acima de $750 \mathrm{~g} /$ dia. O teor de PNDR/PB foi de 38,4; 39,8; 39,2 e 38,5\% respectivamente, para os tratamentos FA0, FA33, FA67 e FA100. Como o teor de PNDR foi similar entre os suplementos, a quantidade de PNDR consumida pelos animais não influenciou no desempenho das bezerras.

O fornecimento de suplementos múltiplos aumentou o consumo de PB e propiciou GMD igual $770 \mathrm{~g} /$ dia, entre os níveis de substituição do farelo de soja pelo FA não houve diferença no consumo de $\mathrm{PB}$, assim como não houve diferença no GMD das bezerras.

Segundo dados de Valadares Filho et al. (2010) vacas de corte com peso corporal de $450 \mathrm{~kg}$, produzindo $6 \mathrm{~kg}$ de leite por dia, com GMD igual a 300 gramas apresentam exigência de 6,02 kg de NDT/dia. Neste estudo o consumo de NDT pelas vacas em $\mathrm{kg} /$ dia foi de 5,1. Em relação à exigência de proteína bruta em vacas lactantes com peso corporal igual $450 \mathrm{~kg}$ e com GMD de 300 gramas a exigência é igual a 715,6 g/dia. Neste estudo o consumo de PB pelas vacas foi de $660 \mathrm{~g} /$ dia. Sendo assim, tanto para o consumo de NDT quanto para o consumo de $\mathrm{PB}$, os resultados encontrados estão de acordo com Valadares Filho et al. (2010).

Um aumento na digestibilidade total pode ser esperado com a inclusão de concentrados na dieta de animais em pastejo pois, apresentam digestibilidades maiores do que a forragem. No entanto, a interação entre a digestão dos concentrados e do pasto pode alterar ou não a digestão da fibra. A suplementação múltipla aumentou a digestibilidade aparente total da MS, MO, PB e CNF. Este aumento pode ser devido à presença de compostos mais facilmente digeríveis na dieta dos animais que receberam suplemento múltiplo, visto que não houve aumento na digestibilidade da FDNcp em resposta ao consumo de suplemento.

$\mathrm{Na}$ Tabela 5 encontram-se as estimativas do coeficiente de digestibilidade aparente total dos constituintes da dieta em função dos tratamentos recebidos pelas bezerras. A suplementação aumentou o coeficiente de digestibilidade aparente total da MS, PB, MO e CNF. No entanto, não houve efeito da suplementação sobre a digestibilidade da FDNcp e sobre o teor de NDT. Houve efeito linear positivo do nível de substituição farelo de soja pelo farelo de algodão (38\% PB) sobre a digestibilidade da PB, EE e CNF. Observou-se efeito linear negativo sobre a digestibilidade da FDNcp.

Os coeficientes de digestibilidade aparente da PB e CNF foram maiores nos animais que receberam suplementos múltiplos, devido ao efeito da menor proporção da fração metabólica fecal em relação ao nutriente ingerido (CABRAL et al., 2006; BARROS et al., 2011). Como o coeficiente de digestibilidade aparente é uma medida relativa, quando se tem baixos consumos de PB, estas perdas metabólicas têm maior capacidade de reduzir a estimativa do coeficiente de digestibilidade da $\mathrm{PB}$, com reflexos sobre o coeficiente de digestibilidade da MS e da MO. Os microrganismos obtêm nitrogênio (N) proveniente da dieta e $\mathrm{N}$ reciclado, resultando na diminuição da proporção de $\mathrm{N}$ endógeno nos compostos nitrogenados fecais à medida que a ingestão de N aumenta (VALADARES et al., 1997; CABRAL et al., 2006).

Observou-se efeito linear positivo do nível de inclusão de FA sobre a digestibilidade aparente total da PB, EE e CNF. O aumento do coeficiente de digestibilidade aparente total da PB, provavelmente ocorreu em razão da maior participação de uréia na composição dos suplementos quando se aumentou o nível de FA nos suplementos, visto que a uréia é rapidamente hidrolisada à amônia no ambiente ruminal. Este efeito também foi observado por Paula et al. (2010). 
Tabela 5. Médias, desvio padrão e indicativos de significância para os coeficientes de digestibilidade aparente total dos componentes da dieta e teor de nitrogênio uréico no soro em bezerras suplementadas e não suplementadas.

\begin{tabular}{|c|c|c|c|c|c|c|c|c|c|}
\hline \multirow{2}{*}{ Item } & \multicolumn{5}{|c|}{ Suplementos } & \multirow{2}{*}{$\begin{array}{l}\text { Desvio } \\
\text { Padrão }\end{array}$} & \multicolumn{3}{|c|}{ Valor - $\mathrm{P}^{1}$} \\
\hline & MM & $\mathrm{FA}_{0}$ & $\mathrm{FA}_{33}$ & $\mathrm{FA}_{67}$ & $\mathrm{FA}_{100}$ & & $\mathrm{CO}$ & $\mathrm{L}$ & $\mathrm{Q}$ \\
\hline Matéria seca $(\mathrm{kg} / \mathrm{kg})$ & 0,7319 & 0,7560 & 0,7703 & 0,7610 & 0,7516 & 0,0348 & 0,0367 & 0,6517 & 0,2954 \\
\hline Matéria orgânica (kg/kg) & 0,7617 & 0,7809 & 0,7950 & 0,7902 & 0,7805 & 0,0034 & 0,0551 & 0,9027 & 0,2843 \\
\hline Proteína bruta $(\mathrm{kg} / \mathrm{kg})^{2}$ & 0,7476 & 0,7705 & 0,7733 & 0,7932 & 0,8034 & 0,0493 & 0,0458 & 0,0974 & 0,8168 \\
\hline Extrato etéreo $(\mathrm{kg} / \mathrm{kg})^{3}$ & 0,8910 & 0,8671 & 0,9022 & 0,9107 & 0,9183 & 0,0513 & 0,6540 & 0,0312 & 0,4084 \\
\hline FDNcp $(\mathrm{kg} / \mathrm{kg})^{4,7}$ & 0,7292 & 0,7557 & 0,7524 & 0,7256 & 0,7228 & 0,0750 & 0,2670 & 0,0006 & 0,9717 \\
\hline $\begin{array}{l}\text { Carboidratos não fibrosos } \\
(\mathrm{kg} / \mathrm{kg})^{5}\end{array}$ & 0,7608 & 0,7718 & 0,8 & 0 & 16 & 33 & 352 & 0,0410 & 0,4165 \\
\hline $\begin{array}{l}\text { Nutrientes digestíveis } \\
\text { totais }(\mathrm{kg} / \mathrm{kg})\end{array}$ & 0,8519 & 0,8366 & 0,8683 & 0,8483 & 0,8718 & 0,0599 & 0,8446 & 0,3191 & 0,8313 \\
\hline $\begin{array}{l}\text { Nitrogênio uréico sérico } \\
(\mathrm{mg} / \mathrm{dL})^{6}\end{array}$ & 8,54 & 9,52 & 11,20 & 11,34 & 12,82 & 2,63 & 0,0068 & 0,0101 & 0,9068 \\
\hline
\end{tabular}

MM: Mistura mineral; $\mathrm{FA}_{0}$ : sem inclusão de farelo de algodão; $\mathrm{FA}_{33}$ : substituição de $33 \%$ do farelo de soja por farelo de algodão; $\mathrm{FA}_{67}$ : substituição de $67 \%$ do farelo de soja por farelo de algodão e $\mathrm{FA}_{100}$ : substituição de $100 \%$ do farelo de soja por farelo de algodão.

${ }^{1}$ Indicativos de significância para contraste entre animais suplementados e não suplementados (CO) e para efeito de ordem linear (L) e quadrática (Q) do nível de substituição do farelo de soja pelo farelo de algodão $38 \%$ nos suplementos. ${ }^{2} \hat{Y}=0,7673+0,0003 \mathrm{x}$ $\left(\mathrm{R}^{2}=0,8998\right) . \quad{ }^{3} \hat{\mathrm{Y}}=0,8753+0,0004 \mathrm{x} \quad\left(\mathrm{R}^{2}=0,9129\right) \cdot{ }^{4} \hat{\mathrm{Y}}=0,7586-0,0003 \mathrm{x} \quad\left(\mathrm{R}^{2}=0,9816\right) . \quad{ }^{5} \hat{\mathrm{Y}}=0,7798+0,0004 \mathrm{x} \quad\left(\mathrm{R}^{2}=0,7518\right)$. ${ }^{6} \hat{Y}=9,7270+0,0301 x\left(R^{2}=0,8024\right) .{ }^{7} \mathrm{FDNcp}$ : Fibra em detergente neutro corrigida para cinzas e proteínas.

Fonte: Elaboração dos autores.

Observou-se efeito linear negativo do nível de FA sobre a digestibilidade da FDNcp. É possível inferir que a provável razão do aumento nos níveis de FA gerarem médias inferiores nos coeficientes de digestibilidade da FDNcp, foi pelo aumento nos níveis de FA nos suplementos aumentarem o teor de FDNi e lignina (Tabela 2).

Os níveis de nitrogênio uréico no soro (NUS) são afetados pelo nível nutricional, sobretudo em ruminantes, e é um indicador sensível e imediato da ingestão de proteína (GONZALES; SCHEFFER, 2002). Assim, as estimativas de NUS têm sido empregadas para se diagnosticar a adequação da utilização de compostos nitrogenados no rúmen em função da disponibilidade de matéria orgânica degradável (SAMPAIO et al., 2009). A concentração de NUS foi maior em bezerras suplementadas em relação as não suplementadas (Tabela 5). Tal fato pode ser atribuído ao maior consumo de PB dos animais suplementados, uma vez que a concentração de NUS está positivamente correlacionada com a ingestão de N. Observou-se efeito linear crescente do nível de farelo de algodão (38\% PB) nos suplementos sobre o teor de NUS.

Valadares et al. (1997) sugeriram que os níveis de N-uréia plasmáticas entre 13,52 e 15,15 mg/ $\mathrm{dL}$ correspondem à máxima eficiência microbiana e provavelmente seria o limite a partir do qual ocorre perda de proteína em novilhos zebuínos alimentados com $62,5 \%$ de NDT. O nível médio de NUS em animais que receberam suplementos múltiplos foi de $11,22 \mathrm{mg} / \mathrm{dL}$ ficando um pouco abaixo do valor mínimo que corresponde a máxima eficiência microbiana sugerido por Valadares et al. (1997). No entanto, o valor de NUS em animais que receberam apenas mistura mineral foi de 8,54 $\mathrm{mg} / \mathrm{dL}$, que estão abaixo daqueles apresentado para animais suplementados, indicando possível comprometimento da atividade microbiana e desempenho dos animais não suplementados.

Não houve diferenças significativas $(P>0,10)$ para o peso corporal final, ganho médio diário 
e escore de condição corporal final das vacas em função dos tratamentos aplicados às suas bezerras, assim como não houve diferenças em relação ao consumo e a digestibilidade dos componentes da dieta.

Na Tabela 6 encontra-se a estatística descritiva das variáveis avaliadas para as vacas.
Não houve diferença $(\mathrm{P}>0,10)$ em relação à produção e composição do leite produzido pelas matrizes (Tabela 6) em função dos tratamentos aplicados às bezerras, indicando que a suplementação das bezerras não alterou o comportamento de amamentação. A média de produção de leite foi de $6,53 \mathrm{~kg}$ por dia, com 3,6\% de proteína bruta, 4,9\% de gordura e $4,4 \%$ de lactose.

Tabela 6. Estatística descritiva das variáveis estudadas nas matrizes.

\begin{tabular}{lcccc}
\hline \multicolumn{1}{c}{ Item } & Mínimo & Média & Máximo & Desvio Padrão \\
\hline Peso corporal inicial (kg) & 325,1 & 436,2 & 555,1 & 50,6 \\
Peso corporal final (kg) & 358,1 & 463,5 & 585,1 & 52,2 \\
Ganho médio diário (kg) & $-0,033$ & 0,307 & 0,567 & 0,141 \\
Escore de condição corporal inicial & 3,2 & 4,3 & 5,6 & 0,6 \\
Escore de condição corporal final & 4,0 & 4,8 & 5,8 & 0,5 \\
Consumo de matéria seca (kg/dia) & 5,9 & 9,3 & 14,3 & 2,1 \\
Consumo de matéria orgânica (kg/dia) & 5,4 & 8,6 & 13,3 & 1,9 \\
Consumo de FDN (kg/dia) & 3,8 & 5,9 & 9,2 & 1,3 \\
Consumo de proteína bruta (kg/dia) & 0,418 & 0,660 & 1,023 & 0,146 \\
Consumo de extrato etéreo (kg/dia) & 0,115 & 0,182 & 0,282 & 0,040 \\
Consumo de carboidratos não fibrosos (kg/dia) & 1,2 & 1,9 & 2,7 & 0,3 \\
Consumo de NDT (kg/dia) & 2,9 & 5,1 & 7,9 & 1,0 \\
Digestibilidade da matéria seca (\%) & 45,8 & 53,8 & 66,9 & 4,5 \\
Digestibilidade da matéria orgânica (\%) & 48,3 & 57,6 & 78,1 & 5,8 \\
Digestibilidade da FDN (\%) & 53,2 & 62,4 & 82,2 & 5,3 \\
Digestibilidade da proteína bruta (\%) & 28,2 & 43,7 & 70,1 & 9,1 \\
Produção de leite (kg/dia) & 1,9 & 6,5 & 10,6 & 1,7 \\
Lactose (\%) & 3,8 & 4,4 & 4,7 & 0,1 \\
Proteína Bruta (\%) & 2,5 & 3,6 & 4,4 & 0,4 \\
Extrato Etéreo (\%) & 3,2 & 4,9 & 6,9 & 0,7 \\
\hline
\end{tabular}

Fonte: Elaboração dos autores.

\section{Conclusões}

A suplementação de bezerras de corte lactentes melhora o desempenho produtivo e nutricional dos animais. O fornecimento de suplementos múltiplos na quantidade de $500 \mathrm{~g} /$ dia não altera o desempenho produtivo e os parâmentros nutricionais das matrizes em lactação. Recomenda-se o fornecimento de suplementos múltiplos formulados com farelo de algodão (38\% PB) para bezerras de corte lactentes criadas em sistema de creep-feeding no período de transição águas-seca.

\section{Agradecimentos}

Ao $\quad \mathrm{CNPq}$ (Conselho Nacional de Desenvolvimento Científico e Tecnológico) pela concessão da bolsa de Pós-Doutorado à primeira autora. 


\section{Referências}

BARROS, L. V.; PAULINO, M. F.; VALADARES FILHO, S. C.; DETMANN, E.; SILVA, F. G.; VALENTE, E. E. L.; LOPES, S. A.; MARTINS, L. S. Replacement of soybean meal by cottonseed meal $38 \%$ in multiple supplements for grazing beef heifers. Revista Brasileira de Zootecnia, Viçosa, v. 40, n. 4, p. 852-859, 2011.

CABRAL, L. S.; VALADARES FILHO, S. C.; DETMANN,E.; MALAFAIA,P.A.M.;ZERVOUDAKIS, J. T.; SOUZA, A. L.; VELOSO, R. G.; NUNES, P. M. $\mathrm{M}$. Consumo e digestibilidade dos nutrientes em bovinos alimentados com dietas à base de volumosos tropicais. Revista Brasileira de Zootecnia, Viçosa, v. 35, n. 6, p. 2406-2412, 2006.

DETMANN, E.; PAULINO, M. F.; ZERVOUDAKIS, J. T.; VALADARES FILHO, S. C.; EUCLIDES, R. F.; LANA, R. P.; QUEIRÓZ, D. S. Cromo e Indicadores internos na determinação do consumo de novilhos mestiços, suplementados, a pasto. Revista Brasileira de Zootecnia, Viçosa, v. 30, n. 5, p. 1600-1609, 2001.

GELVIN, A. A.; LARDY, G. P.; SOTO-NAVARRO, S. A.; LANDBLOM, D. G.; CATON, J. S. Effect of fild pea-based creep feed on intake, digestibility, ruminal fermentation, and performance by nursing calves grazing native range in western North Dakota. Journal of Animal Science, Champaign, v. 82, n. 12, p. 3589-3599, 2004.

GONZALES, F. H. D.; SCHEFFER, J. F. S. Perfil sanguíneo: ferramenta na análise clínica, metabólica e nutricional. Avaliação metabólica-nutricional de vacas leiteiras por meio de fluídos corporais. In: CONGRESSO BRASILEIRO DE MEDICINA VETERINÁRIA, 2002, Gramado. Anais... Gramado: Félix H.D. González, 2002. p. 5-17.

HALL, M. B.; AKINYODE, A. Cottonseed hulls: working with a novel fiber source. In: ANNUAL FLORIDA RUMINANT NUTRITION SYMPOSIUM, 11., 2000, Gainesville. Proceedings... Gainesville: University of Florida, 2000. p. 179-186.

HENRIQUES, L. T.; VALADARES FILHO, S. C.; FONSECA, M. A.; PAULINO, P. V. R.; VALADARES, R. F. D. Avaliação de modelos não-lineares e da relação do consumo voluntário de vacas primíparas e de bezerros com a curva de lactação de vacas Nelore. Revista Brasileira de Zootecnia, Viçosa, v. 40, n. 6, p. 1287-1295, 2011.

KRESS, D. D.; DOORNBOS, D. E.; ANDERSON, D. C. Performance of crosses among Hereford, Angus and Simental cattle with different levels of simental breeding: V. Calf production, milk production and reproduction of three to eight year old dams. Journal of Animal Science, Champaign, v. 68, n. 7, p. 1910-1921, 1990.
LAZZARINI, I.; DETMANN, E.; SAMPAIO, C. B.; PAULINO, M. F.; VALADARES FILHO, S. C.; SOUZA, M. A.; OLIVEIRA, F. A. Intake and digestibility in cattle fed low-quality tropical forage and supplemented with nitrogenous compounds. Revista Brasileira de Zootecnia, Viçosa, v. 38, n. 10, p. 2021-2030, 2009.

MERTENS, D. R. Gravimetric determination of amylasetreated neutral detergent fiber in feeds with refluxing in beaker or crucibles: collaborative study. Journal of AOAC International, Gaithersburg, v. 85, n. 6, p. 1217 1240, 2002.

NATIONAL RESEARCH COUNCIL - NRC. Nutrient requirements of beef cattle. 7. ed. Washington, D.C.: National Academy, 1996. 242 p.

OLIVEIRA, R. L.; BARBOSA, M. A. A. F.; LADEIRA, M. M.; SILVA, M. M. P.; ZIVIANI, A. C.; BAGALDO, A. R. Nutrição e manejo de bovinos de corte na fase de cria. Revista Brasileira de Saúde e Produção Animal, Salvador, v. 7, n. 1, p. 57-86, 2006.

PAULA, N. F.; ZERVOUDAKIS, J. T.; CABRAL, L. S.; CARVALHO, D. M. G.; ZERVOUDAKIS, L. K. H.; MORAES, E. H. B. K.; OLIVEIRA, A. A. Frequência de suplementação e fontes de proteína para recria de bovinos em pastejo no período seco: desempenho produtivo e econômico. Revista Brasileira de Zootecnia, Viçosa, v. 39, n. 4, p. 873-882, 2010.

PAULINO, M. F.; DETMANN, E.; VALADARES FILHO, S. C. Bovinocultura funcional nos trópicos. In: SYMPOSIUM OF BEEF CATTLE PRODUCTION, 7., 2008, Viçosa, MG. Proceedings... Viçosa, MG: Departamento de Zootecnia, UFV, 2008. p. 275-305.

PAULINO, M. F. Estratégias de suplementação para bovinos de corte. In: SYMPOSIUM OF BEEF CATTLE PRODUCTION, 1., 1999, Viçosa, MG. Proceedings... Viçosa, MG: Departamento de Zootecnia, UFV, Viçosa, MG, 1999. p. 93-139.

PAULINO, M. F.; FIGUEIREDO, D. M.; MORAES, E. H. B. K.; PORTO, M. O.; SALES, M. F. L.; ACEDO, T. S.; VILlELA, S. D. J.; VALADARES FILHO, S. C. Suplementação de bovinos em pastagens: uma visão sistêmica. In: SYMPOSIUM OF BEEF CATTLE PRODUCTION, 4., 2004, Viçosa, MG. Proceedings... Viçosa, MG: Departamento de Zootecnia, UFV, Viçosa, MG, 2004. p. 93-139.

SAMPAIO, C. B.; DETMANN, E.; LAZZARINI, I.; SOUZA, M. A.; PAULINO, M. F.; VALADARES FILHO, S. C. Rumen dynamics of neutral detergent fiber in cattle fed low-quality tropical forage and supplemented with nitrogenous compounds. Revista Brasileira de Zootecnia, Viçosa, v. 38, n. 3, p. 560-569, 2009. 
SILVA, D. J.; QUEIROZ, A. C. Análise de alimentos: métodos químicos e biológicos. 3. ed. Viçosa: UFV, imp. Univ., 2002. 165 p.

TITGEMEYER, E. C.; ARMENDARIZ, C. K.; BINDEL, D. J.; GREENWOOD, R. H.; LOEST, C. A. Evaluation of titanium dioxide as a digestibility marker for cattle. Journal of Animal Science, Champaign v. 79, n. 4, p. 1059-1063, 2001.

VALADARES FILHO, S. C.; MARCONDES, M. I., CHIZZOTTI, M. L., PAULINO, P. V. R. Exigências nutricionais de zebuínos puros e cruzados BR-CORTE. 2. ed. Viçosa: DZO/UFV, 2010. 193 p.

VALADARES, R. F. D.; GONÇALVES, L. C.; RODRIGUEZ, N. M.; VALADARES FILHO, S. C.; SILVA, J. F. C. Níveis de proteína em dietas de bovinos. 2. Consumo, digestibilidade e balanço de compostos nitrogenados. Revista Brasileira de Zootecnia, Viçosa, v. 26, n. 6, p. 1259-1263, 1997.

VALENTE, É. E. L.; PAULINO, M. F.; DETMANN, E.; VALADARES FILHO, S. C.; BARROS, L. V.; ACEDO, T. S.; COUTO, V. R. M.; LOPES, S. A. Levels of multiple supplements or nitrogen salt for beef heifers in pasture during the dry season. Revista Brasileira de Zootecnia, Viçosa, v. 40, n. 9, p. 2011-2019, 2011 a.
VALENTE, É. E. L.; PAULINO, M. F.; DETMANN, E.; VALADARES FILHO, S. C.; BARROS, L. V.; CABRAL, C. H. A.; SILVA, A. G.; DUARTE, M. S. Strategies of supplementation of female suckling calves and nutrition parameters of beef cows on tropical pasture. Tropical Animal Health and Production, Netherlands, v. 44, n. 7, p. 1803-1811, 2012.

VALENTE, T. N. P.; DETMANN, E.; QUEIROZ, A. C.; VALADARES FILHO, S. C.; GOMES, D. I.; FILGUEIRAS, J. F. Evaluation of rumen degradation profiles of forages using bags made from different textiles. Revista Brasileira de Zootecnia, Viçosa, v. 40, n. 11, p. 2565-2573, 2011 b.

VAN SOEST, P. J.; ROBERTSON, J. B. Analysis of forages and fibrous foods. Ithaca: Cornell University, 1985. 202 p.

WILLIANS, C. H.; DAVID, D. J.; IISMA, O. The determination of chromic oxide in faeces samples by atomic absorption spectrophotometry. Journal of Agricultural Science, Cambridge, v. 59, n. 3, p. 381-385, 1962. 
